\title{
Rapid determination of natural steroidal hormones in saliva for the clinical diagnoses
}

Jin-Aa Oh ${ }^{1}$ and Ho-Sang Shin ${ }^{2^{*}}$

\begin{abstract}
Background: Saliva samples are easily collectable and non-invasive, and the monitoring of natural steroidal hormones, such as estrone (E1), 17ß-estradiol (E2), estriol (E3), progesterone $(P)$, and testosterone $(T)$, in saliva has attracted much attention due to its numerous potential clinical and health-related applications. Because E1, E2, E3, $\mathrm{P}$ and $\mathrm{T}$ are useful indicators in numerous clinical and health-related diagnoses, there is a need for simultaneous determination.

Results: A gas chromatography-mass spectrometric assay was developed for rapid simultaneous determination of E1, E2, E3, P and T in saliva for clinical diagnoses. Extraction was achieved with a liquid extraction using $3.0 \mathrm{~mL}$ of pentane. The extract was dried and silylated with $\mathrm{N}$-methyl-N-(trimethylsilyl) trifluoroacetamide/ $\mathrm{NH}_{4} \mathrm{l}(100: 2)$ under a catalysis of $1.5 \%$ dithioerythritol for $10 \mathrm{~min}$ at $90^{\circ} \mathrm{C}$. The accuracy of the analytes was in the range of $96 \%$ to $112 \%$ at concentrations of 0.05 and $0.10 \mu \mathrm{g} / \mathrm{L}(5.0$ and $10.0 \mu \mathrm{g} / \mathrm{L}$ for E3), respectively, with relative standard deviations of less than $11 \%$. The lowest quantification limits were from 0.002 to $0.6 \mu \mathrm{g} / \mathrm{L}$ for $1.0 \mathrm{~mL}$ of saliva.

Conclusion: Natural steroidal hormones were detected in the concentration ranges of nd to $0.2 \mu \mathrm{g} / \mathrm{L}$ in human saliva. The salivary testosterone values in the patients with prostatic carcinoma were significantly lower than in normal males. The method may useful in numerous clinical and health-related diagnoses.
\end{abstract}

Keywords: Clinical diagnosis, Natural steroidal hormones, Saliva, GC-MS

\section{Background}

Saliva samples are easily collectable, non-invasive, and pose no risk to the health of the subjects. Salivary concentrations of steroids generally reflect serum concentrations of free active steroids; a significant correlation between salivary and serum steroid concentrations was shown in men [1-4]. Therefore, saliva has been used in a number of human and nonhuman studies to determine the presence of a wide range of substances, including biological substances and pharmaceutical drugs [5]. The monitoring of natural steroidal hormones, such as estrone (E1), 17 $\beta$-estradiol (E2), estriol (E3), progesterone $(\mathrm{P})$, and testosterone $(\mathrm{T})$, in saliva has attracted much attention due to its numerous potential clinical and health-related applications [1-4,6-14].

Clinical monitoring of E2 is desirable for the study and treatment of hormone-dependent carcinomas [5],

\footnotetext{
* Correspondence: hshin@kongju.ac.kr

${ }^{2}$ Department of Environmental Education, Kongju National University,

Kongju, Korea 314-701, South Korea

Full list of author information is available at the end of the article
}

and investigating ovarian function [6]. The measurement of salivary E3 concentrations could be useful in evaluating antidepressant use during pregnancy [7] and the simultaneous measurement of salivary E3 and P concentrations could be useful in the prediction of preterm birth [8]. Measurement of salivary E1 and salivary T could give useful information in evaluating of pregnant sows [9], and the androgenic function of patients with prostatic carcinoma after medical or surgical orchiectomy [10] and late-onset hypogonadism [11,12], respectively. Monitoring T in children's saliva affords a unique view of the effects of behavioral factors on development [15].

Many analytical procedures have been proposed to determine trace level for natural steroidal compounds in saliva, most of which are based on determining E1 [9], E2 [16], E3 [17,18], P [18], and T [19] levels in saliva using enzyme immunoassay. Although this technique will continue to be the method of choice for routine use in clinical fields, especially in large population-based 
tests, it does not have a simultaneous multianalyte quantification capability.

Recently, liquid chromatography-tandem mass spectrometric (LC-MS/MS) methods has been developed and validated for the quantification of salivary $\mathrm{T}$ $[4,12,20,21]$. These methods are restrictive for the quantification of salivary $\mathrm{T}$, and require complicated cleanup procedures and expensive instruments.

Several researchers have analyzed the salivary $\mathrm{T}$ in human saliva using a gas chromatography-mass spectrometry after the $t$-butyldimethylsilyl ether and methyl oxime, $t$-butyldimethylsilyl ether derivatization $[22,23]$. These methods are also restrictive for the quantification of salivary $\mathrm{T}$, and require immunoadsorption as sample treatment. Silylation is a versatile method used to derivatize the organic compounds that contain the hydroxyl group to enhance the GC-MS properties. Reduction of reaction time may be more effective in determining the natural steroids in saliva.

The purpose of the present study is to develop a sensitive and simultaneous determination method for natural steroidal hormones (E1, E2, E3, P and T) in saliva and to evaluate the increased risk of various disorders.

\section{Experimental}

\section{Chemicals and reagents}

The following chemicals were purchased from Sigma (St. Louis, MO, USA): estrone, $17 \beta$-estradiol, estriol, progesterone, testosterone, testosterone- $\mathrm{d} 3$, dithioerythritol, $\mathrm{NH}_{4} \mathrm{I}$ and $N$-methyl- $N$-(trimethylsilyl) trifluoroacetamide (MSTFA). For the reagent, analytical grade sodium sulfate (Sigma, St. Louis, MO, USA) was used. Acetonitrile and pentane (E. Merck, Darmstadt, Germany) were used for the solvents.

\section{Collection and extraction procedure of saliva}

The study was approved by the institutional review board at the Kongju national university, and written informed consent was obtained from each subject. Saliva (ca. $1.2 \mathrm{~mL}$ ) was directly collected into a collecting tube (without a collection device) from 10 volunteers who did not take hormone supplements or drugs that influence steroid hormone biosynthesis and metabolism. The volunteers did not smoke, eat and drink or brush their teeth within $1 \mathrm{~h}$ prior to the sample collection. Saliva (ca. $1.2 \mathrm{~mL}$ ) was also taken from five patients with prostatic carcinoma under the treatment in a University Hospital (Dejoen, Korea). The sample collection time was between ten and eleven o'clock in the morning. It was stored in a glass collection tube below $-20^{\circ} \mathrm{C}$ until use. After thawing, a $1.0 \mathrm{~mL}$ sample was placed in a 10 $\mathrm{mL}$ test tube and $25.0 \mu \mathrm{L}$ of a testosterone-d3 internal standard solution $(10.0 \mu \mathrm{g} / \mathrm{L}$ in acetonitrile) was added to the solution. The solution was extracted with $3.0 \mathrm{~mL}$ of pentane by subjecting the mixture to vortex mixing for $1 \mathrm{~min}$ after adding $3.0 \mathrm{~g}$ of dried sodium sulfate. The organic phase was dried in nitrogen stream.

\section{Derivatization}

The dry residue was dissolved with $50 \mu \mathrm{L}$ of silylating reagents (MSTFA $+2.0 \% \mathrm{NH}_{4} \mathrm{I}+1.5 \%$ dithioerythritol, $v / w / w)$ and the tubes were heated for $10 \mathrm{~min}$ at $90^{\circ} \mathrm{C}$, and a $2 \mu \mathrm{L}$ sample of the solution was injected into the GC system.

\section{Gas chromatography-mass spectrometry}

All mass spectra were obtained with an Agilent 6890/ 5975 instrument. The ion source was operated in the electron ionization mode (EI; $\left.70 \mathrm{eV}, 230^{\circ} \mathrm{C}\right)$. Full-scan mass spectra $(\mathrm{m} / \mathrm{z} 40-800)$ were recorded for the analyte identification. Separation was achieved with a HP fusedsilica capillary column with a cross-linked 5\% phenyl methylsilicone (DB 5); the column has a length of approximately $30 \mathrm{~m}$, an inner diameter of $0.25 \mathrm{~mm}$ and a film thickness of $0.25 \mu \mathrm{m}$. Samples were injected in a splitless mode. The flow rate of the helium was $1.0 \mathrm{~mL} /$ min.

The operating parameters were as follows: injector temperature, $310^{\circ} \mathrm{C}$; transfer line temperature, $300^{\circ} \mathrm{C}$; and oven temperature, programmed from $150^{\circ} \mathrm{C}$ at $12^{\circ}$ $\mathrm{C} / \mathrm{min}$ to $310^{\circ} \mathrm{C}$ (hold for $4 \mathrm{~min}$ ). The ions that were selected for monitoring by the SIM were $m / z$ 414, 399 and 309 for E1, $m / z$ 416, 326 and 285 for E2, $m / z$ 504, 345 and 311 for E3, $m / z$ 458, 443 and 157 for P, $m / z$ 432, 417, and 208 for $\mathrm{T}$, and $\mathrm{m} / z$ 435, 420, and 209 for $\mathrm{T}-\mathrm{d} 3$ (internal standard).

\section{Calibration and quantification}

The calibration curves for the E1, E2, E3, P and T were established through extraction and derivatization after the addition of $0.002,0.010,0.025,0.050$ and $0.10 \mathrm{ng} /$ $\mathrm{mL}$ of the standards and $0.25 \mathrm{ng} / \mathrm{mL}$ of the internal standard into $1.0 \mathrm{~mL}$ of saliva. Saliva $(c a .1 .2 \mathrm{~mL})$ for the calibration curve was collected from healthy volunteer, who did not smoke, eat and drink or brush their teeth within $1 \mathrm{~h}$ prior to the sample collection. The ratio of the standard peak area to that of the internal standard was used in the quantification of the compound. The quantification ion was $m / z 414$ for E1, $m / z$ 416 for E2, $m / z 504$ for E3, $m / z 458$ for $\mathrm{P}, m / z 432$ for $\mathrm{T}$, and $m / z 435$ for T-d3 (internal standard)

\section{Results and discussion \\ Derivatization}

E1, E2, E3, P and T contain more than one derivatizable functional group. E1 has a hydroxyl group in the aromatic ring and an enolic carbonyl group, and E2 and E3 contain a hydroxyl group of the aromatic ring and one 
or two hydroxyl groups of the aliphatic ring, respectively. P contains two carbonyl groups and $\mathrm{T}$ contains a carbonyl group and a hydroxyl group of the aliphatic ring (Table 1).

To develop a rapid derivatization method of steroids with multi-functional groups, the first attempt located the condition in order to silylate only at the hydroxyl group of the steroid under mild condition using MSTFA. However, it was unsuccessful because the derivatization was not quantitative. Furthermore, an attempt to develop a rapid derivatization method for all functional groups of steroids by changing the amount of catalyzing agents, the reaction temperature, and reaction time was also undertaken. The MSTFA as a silylating reagent and $\mathrm{NH}_{4}-\mathrm{I} /$ dithioerythritol as catalyzing agents were tested in terms of the reactivity of the derivatives. The derivatization was performed for various $\mathrm{NH}_{4}$-I and dithioerythritol concentrations $(0.3,1.0,1.5,2.0,3.0,4.0$ and 5.0 wt \% to MSTFA weight). The rapid derivatization was reached with $2.0 \%$ of $\mathrm{NH}_{4}$ - $\mathrm{I}$ and $1.5 \%$ of dithioerythritol and the yield remained beyond the catalyzing agent amount.

The derivatives were analyzed at reaction times of 10 , 20, 30, 40 and $60 \mathrm{~min}$ at 85,90 and $95^{\circ} \mathrm{C}$. When the reaction temperature and time increased to $90^{\circ} \mathrm{C}$ and 10 min, the derivatization yield achieved its maximum.
As a result, the steroids showed a rapid and complete reaction in $10 \mathrm{~min}$ at $90^{\circ} \mathrm{C}$ with MSTFA/ $\mathrm{NH}_{4}-\mathrm{I}(100: 2)$ containing 1.5\% dithioerythritol. A ketone group of E1 and $\mathrm{T}$, and two ketone groups of $\mathrm{P}$ were completely converted to TMS-enol in $10 \mathrm{~min}$ in these conditions.

\section{Method validation}

Figure 1 and 2 show chromatograms of the bis-TMS-E1, bis-TMS-E2, tri-TMS-E3, bis-TMS-P, bis-TMS-T and bis-TMS-T-d3 in the standard solution and a real sample. The peaks are symmetrical and no tailing can be seen. There are no extraneous peaks observed in the chromatogram of the sample at the analyte retention times. The retention times of bis-TMS-E1, bis-TMS-E2, bis-TMS-T-d3, bis-TMS-T, tri-TMS-E3 and bis-TMS-P were $11.29,11.42,11.44,11.45,12.70$ and $12.79 \mathrm{~min}$, respectively.

The mass fragmentation of the analytes under electron ionization at $70 \mathrm{eV}$ is summarized in Table 2. The molecular ion and the fragment ions formed by the loss of a methyl group, HOTMS, OTMS $+\mathrm{CH}_{4}$ and TMS$\mathrm{O}-\mathrm{CH}_{2}-\mathrm{CH}_{3}$ from the molecular ion were characteristic.

Liquid-liquid extraction (LLE) with pentane was selected for the rapid extraction of steroids in saliva and the use of dried sodium sulfate in the sample allow the most water to remove from the sample, to increase the recovery of

Table 1 Molecular formula and mass of target compounds and their derivatives

\begin{tabular}{|c|c|c|c|c|c|c|c|c|}
\hline \multicolumn{6}{|c|}{ Steroids } & \multicolumn{3}{|c|}{ Corresponding Derivative Products } \\
\hline $\begin{array}{l}\text { Full } \\
\text { Name }\end{array}$ & $\begin{array}{l}\text { Short } \\
\text { Name }\end{array}$ & $\begin{array}{l}\text { Chemspider } \\
\text { ID }\end{array}$ & $\begin{array}{c}\text { Molecular } \\
\text { Formula }\end{array}$ & Molecular Weight & Structure & $\begin{array}{l}\text { Short } \\
\text { Name }\end{array}$ & $\begin{array}{l}\text { Molecular } \\
\text { Formula }\end{array}$ & Molecular Weight \\
\hline Estrone & E1 & 5660 & $\mathrm{C}_{18} \mathrm{H}_{22} \mathrm{O}_{2}$ & 270.4 & & bis-TMS-E1 & $\mathrm{C}_{24} \mathrm{H}_{38} \mathrm{O}_{2} \mathrm{Si}_{2}$ & 414.3 \\
\hline $17 \beta$-Estradiol & E2 & 5554 & $\mathrm{C}_{18} \mathrm{H}_{24} \mathrm{O}_{2}$ & 272.4 & & bis-TMS-E2 & $\mathrm{C}_{24} \mathrm{H}_{40} \mathrm{O}_{2} \mathrm{Si}_{2}$ & 416.4 \\
\hline Progesterone & $P$ & 5773 & $\mathrm{C}_{21} \mathrm{H}_{30} \mathrm{O}_{2}$ & 314.5 & & bis-TMS-P & $\mathrm{C}_{27} \mathrm{H}_{46} \mathrm{O}_{2} \mathrm{Si}_{2}$ & 458.3 \\
\hline Testosterone & $\mathrm{T}$ & 5791 & $\mathrm{C}_{19} \mathrm{H}_{28} \mathrm{O}_{2}$ & 288.4 & & bis-TMS-T & $\mathrm{C}_{25} \mathrm{H}_{44} \mathrm{O}_{2} \mathrm{Si}_{2}$ & 432.3 \\
\hline Estriol & E3 & 5553 & $\mathrm{C}_{18} \mathrm{H}_{24} \mathrm{O}_{3}$ & 288.4 & & tri-TMS-E3 & $\mathrm{C}_{27} \mathrm{H}_{48} \mathrm{O}_{3} \mathrm{Si}_{3}$ & 504.4 \\
\hline
\end{tabular}


E1

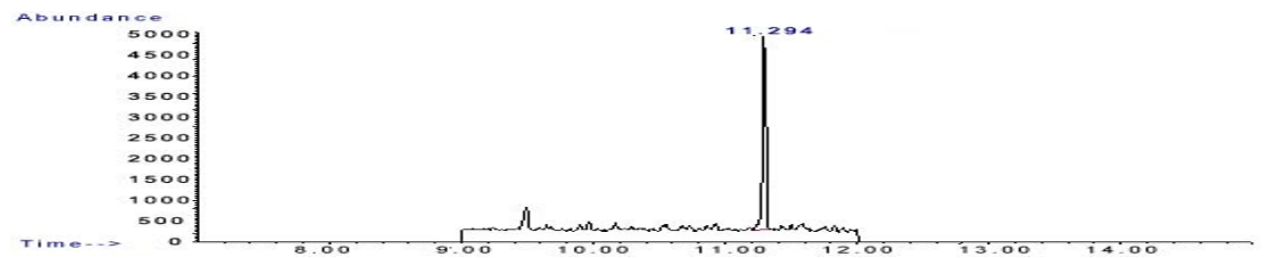

E2

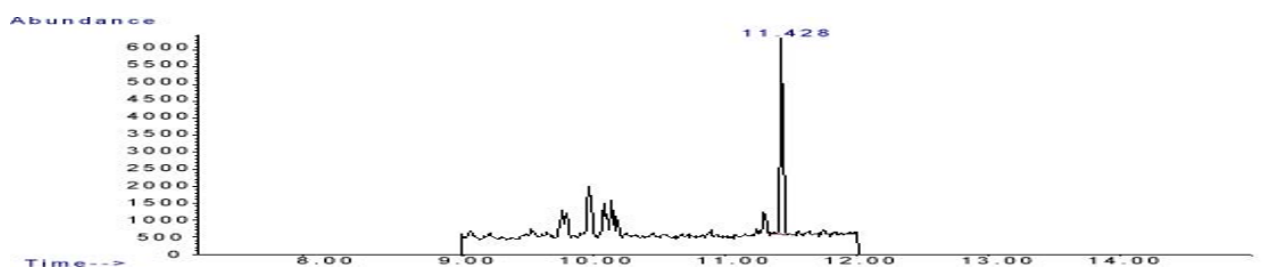

E3

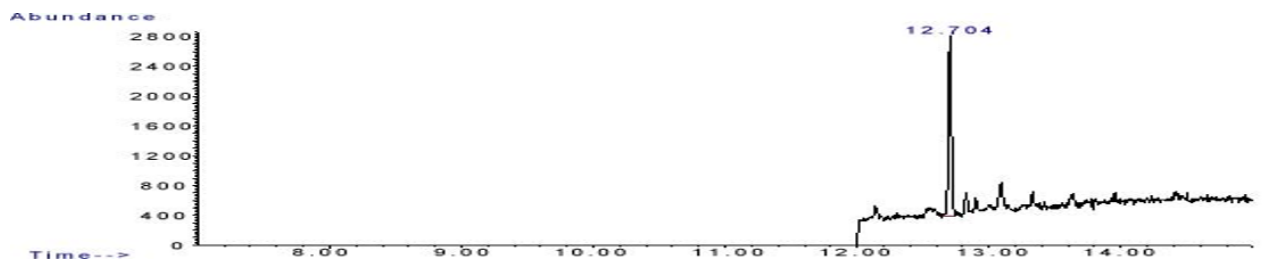

$\mathbf{P}$

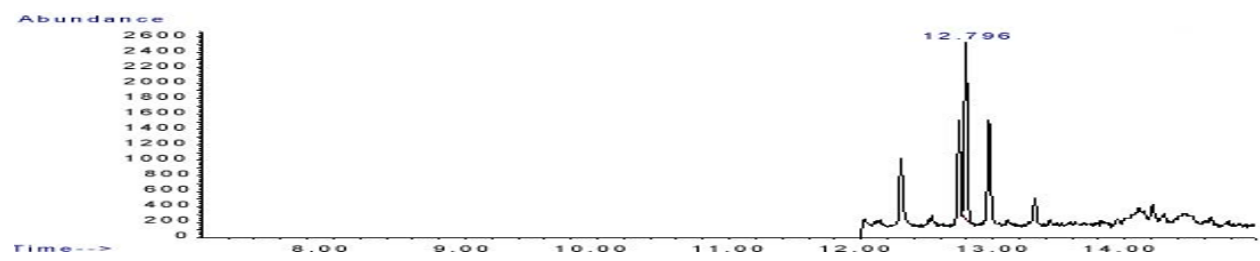

T Abundanoe

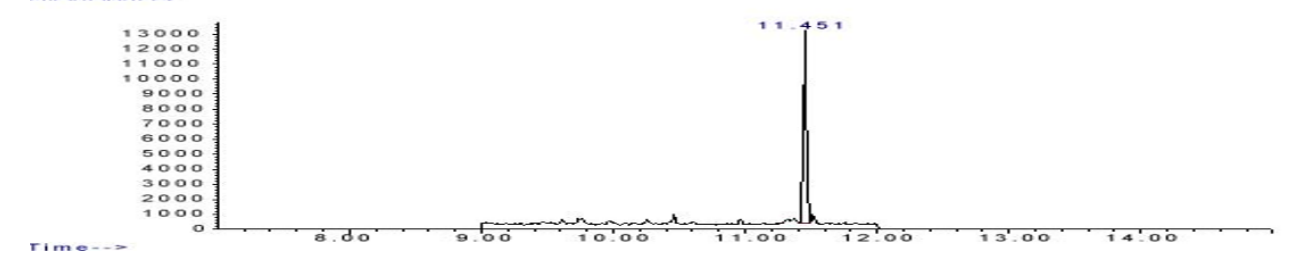

T-d3

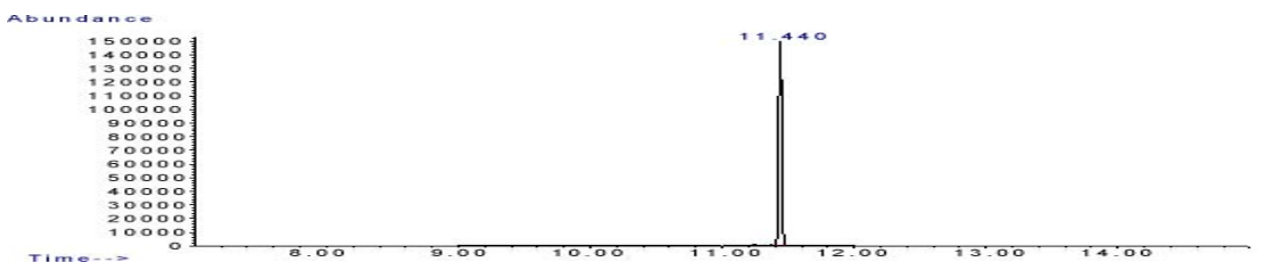

Figure $1 \mathrm{GC}-\mathrm{MS}$ chromatogram after the extraction and derivatization of saliva spiked in concentration of $0.10 \mu \mathrm{g} / \mathrm{L}$ (that of estriol $=$ $2.0 \mu \mathrm{g} / \mathrm{L})$

steroids from the saliva, and to decant the organic phase without centrifugation. The total sample treatment time including derivatization was reduced to $20 \mathrm{~min}$.
Five saliva samples spiked at a concentration of 0.05 and $0.10 \mu \mathrm{g} / \mathrm{L}$ were prepared and the relative recovery was calculated in terms of the percentage of derivatives 


\section{Blank}

$\mathrm{m} / \mathrm{z}=\mathbf{4 1 6}$

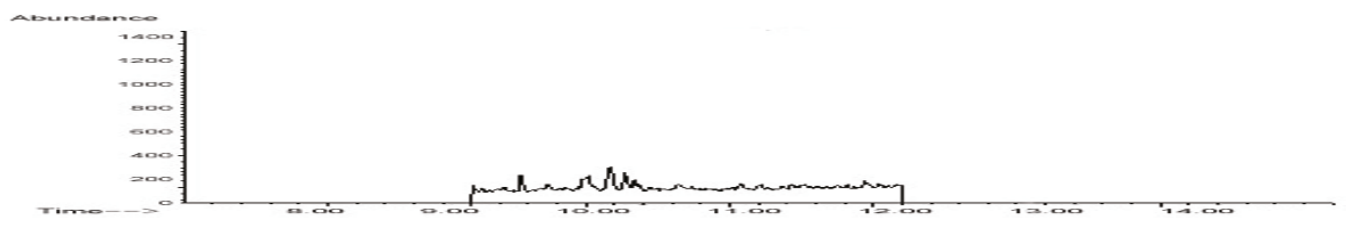

$\mathrm{m} / \mathrm{z}=432$

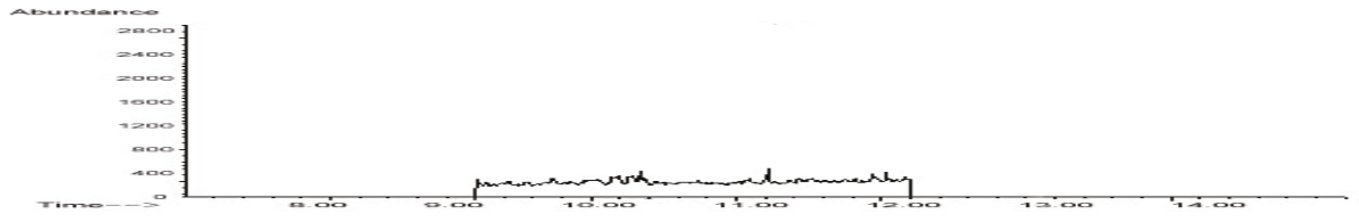

$\mathrm{m} / \mathrm{z}=\mathbf{4 5 8}$

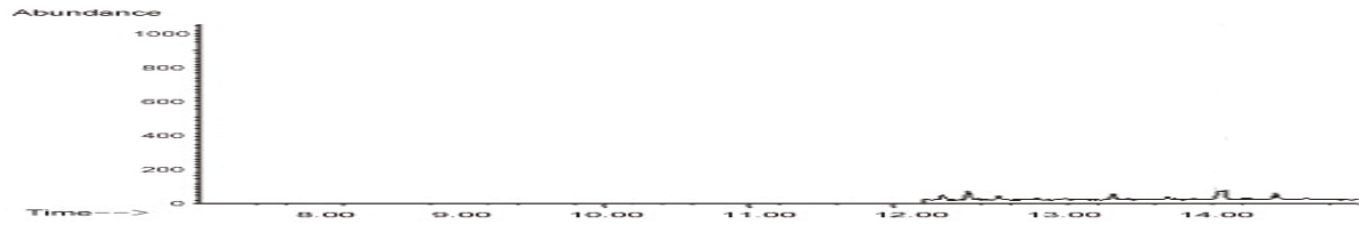

\section{Real sample}

$\mathrm{m} / \mathrm{z}=416$

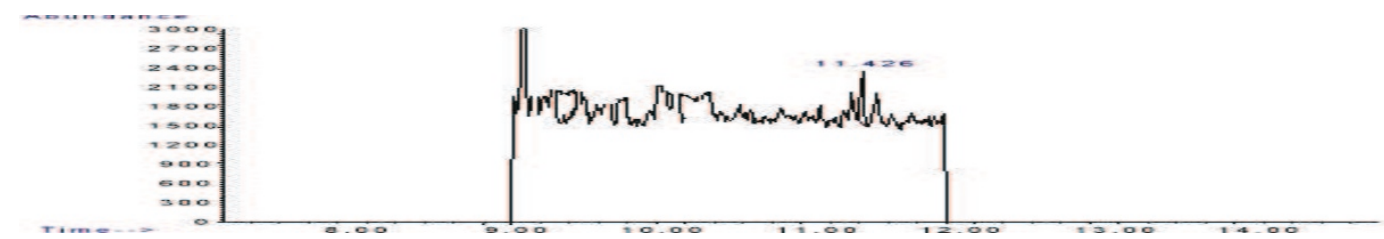

$\mathrm{m} / \mathrm{z}=432$

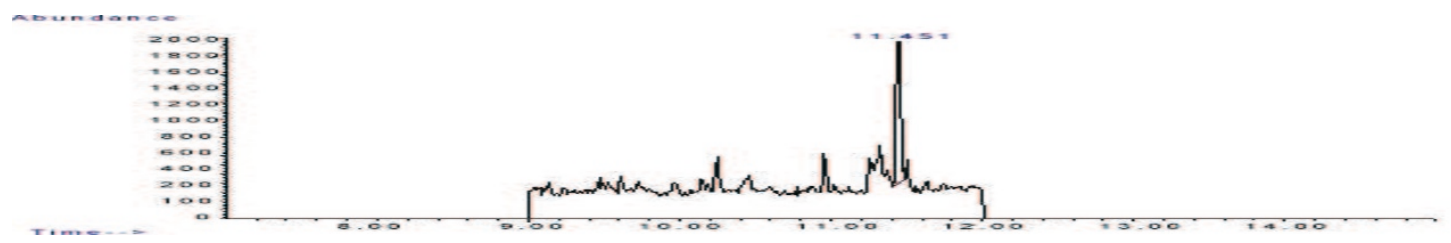

$\mathrm{m} / \mathrm{z}=\mathbf{4 5 8}$
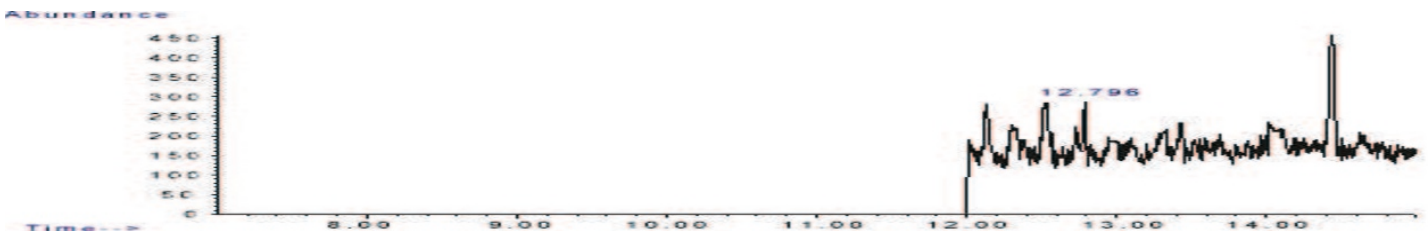

Figure 2 GC-MS chromatogram after the extraction and derivatization of blank and real saliva sample. The concentrations of estradiol $(\mathrm{m} / \mathrm{z} 414)$, progesterone $(\mathrm{m} / \mathrm{z} 458)$ and testosterone $(\mathrm{m} / \mathrm{z} 432)$ were $0.008 \mu \mathrm{g} / \mathrm{L}, 0.013 \mu \mathrm{g} / \mathrm{L}$ and $0.035 \mu \mathrm{g} / \mathrm{L}$, respectively.

recovered. The recovery values of E1, E2, E3, P, and T were between $93 \%$ and $111 \%$ as described in Table 3 .

A linear relation with an average correlation coefficient of 0.999 was found in the examination of a typical standard curve. A least squares fit was used to compute the regression line of the peak area ratios of the bisTMS-E1, bis-TMS-E2, tri-TMS-E3, bis-TMS-P and bisTMS-T to bis-TMS-T-d3 on concentrations. Table 3 
Table 2 Mass fragmentation of steroid derivatives

\begin{tabular}{|c|c|c|c|c|c|c|c|}
\hline Derivative & $\mathrm{M}^{+}$ & $\mathrm{M}^{+}-\mathrm{CH}_{3}$ & $\mathrm{M}^{+}$- HOTMS & $\mathrm{M}^{+}$- OTMS-CH & $\mathrm{M}^{+}-\mathrm{TMSO}-\mathrm{CH}_{2}-\mathrm{CH}_{3}$ & D-ring cleavage & Others \\
\hline di-TMS-E1 & $414(87.2)^{*}$ & $* * 399(55.1)$ & - & $* * 309(16.6)$ & - & $285(4.8)$ & $231(4.3)$ \\
\hline di-TMS- $\alpha-E 2$ & $416(94.1)^{*}$ & $401(7.1)$ & $* * 326(10.6)$ & $309(3.5)$ & $298(9.4)$ & $* * 285(72.4)$ & 129(32.4) \\
\hline tri-TMS-E3 & $504(76.9)^{*}$ & $489(9.3)$ & $414(7.7)$ & $399(5.0)$ & $386(26.4)$ & $285(23.7)$ & ${ }^{* *} 345(39.6), * * 311(36.8)$ \\
\hline di-TMS-P & $458(63.5)^{*}$ & $* * 443(46.5)$ & - & $353(4.1)$ & - & - & **157(32.9) \\
\hline di-TMS-T & $432(100)^{*}$ & $*^{* *} 417(13.1)$ & $342(1.3)$ & $327(2.0)$ & - & - & $* * 208(11.1)$ \\
\hline di-TMS-T-d3 & $435(100)^{*}$ & $* * 420(16.9)$ & $345(1.5)$ & $330(2.4)$ & - & - & $* * 209(17.5)$ \\
\hline
\end{tabular}

${ }^{*}=$ the quantification ion; ${ }^{*}=$ the qualification ion; ()$=$ relative abundance

shows the lines of the best fit and the correlation coefficients for the steroids.

Table 3 confirms that the reproducibility of the assay was very good. For the five independent determinations at 0.05 and $0.10 \mu \mathrm{g} / \mathrm{L}$, the coefficient of variation was less than $11 \%$.

The limit of detection (LOD) and the limit of quantification (LOQ) were defined as the analyte concentration corresponding to a signal/noise ratio of 3 and 10 from samples $(n=7)$ spiked at the concentration of $0.01 \mu \mathrm{g} / \mathrm{L}$ in saliva. LOQs were $0.003 \mu \mathrm{g} / \mathrm{L}$ for $\mathrm{E} 1, \mathrm{P}$ and $\mathrm{T}, 0.002$ $\mu \mathrm{g} / \mathrm{L}$ for $\mathrm{E} 2$ and $0.3 \mu \mathrm{g} / \mathrm{L}$ for E3 using a $1.0 \mathrm{~mL}$ of saliva. Table 4 compares various analytical methods for determining 5 steroids in saliva. The method permits the determination of 5 steroids well below or similar those reported previously $[8,9,11,13,16,19]$.

\section{Real sample analysis}

The target compounds in 10 healthy volunteer and 5 patient saliva samples were analyzed. Confirmation of trace analytes was achieved by use of three characteristic MS ions. The characteristic ion ratios and GC retention times were matched with those of standard compounds.

Analytical results of natural steroidal hormones in saliva were shown in Table 5. In this study, the female subjects had E2 and P salivary concentrations of 0.008 to $0.016 \mu \mathrm{g} / \mathrm{L}$ and 0.009 to $0.028 \mu \mathrm{g} / \mathrm{L}$, respectively, while these were not detected in the saliva of the male subjects. Generally, E2 and P levels are used to assess fertility, ovarian function and long term health (reduction in heart disease and osteoporosis) in the concentration range of 0.002 to $0.05 \mu \mathrm{g} / \mathrm{L}[6,8]$. The proposed method had enough sensitivity to be beneficial in evaluating the disorders.

The salivary $\mathrm{T}$ concentrations of healthy volunteers were in a range of 0.032 to $0.040 \mu \mathrm{g} / \mathrm{L}$ in the female subjects, and in a range of 0.077 to $0.200 \mu \mathrm{g} / \mathrm{L}$ in the male subjects in this study. Otherwise, testosterone concentrations in saliva 5 patients with prostatic carcinoma were measured in a range of not detected to $0.027 \mu \mathrm{g} / \mathrm{L}$. The salivary testosterone values in these patients were significantly lower than in normal males. The proposed method also has sufficient sensitivity for the estimate of the androgenic function of patients with prostatic carcinoma.

E1 and E3 were not detected in any saliva samples in this study. The normal concentration range fell below the detectability levels of this method. Heine et al. reported that an E3 measurement of $2.1 \mu \mathrm{g} / \mathrm{L}$ predicted an increased risk of preterm labor and delivery [24]. Elevated levels of estriol $(0.9-2.1 \mu \mathrm{g} / \mathrm{L})$ are an indication of preterm births [8] and show higher than LOQ $(0.3 \mu \mathrm{g} /$ L) of E3 using the proposed method. The results suggest that the measurement of salivary E3 concentration using the proposed method can evaluate the increased risk of preterm labor and delivery.

Table 3 Method validation results of the target compounds

\begin{tabular}{|c|c|c|c|c|c|c|c|}
\hline \multirow[t]{2}{*}{ Compound } & \multirow{2}{*}{$\begin{array}{l}\text { Retention Time } \\
\text { (min) }\end{array}$} & \multicolumn{2}{|c|}{ Calibration curve } & \multicolumn{3}{|c|}{ Precision and Accuracy $(n=5)$} & \multirow{2}{*}{$\begin{array}{c}\text { Recovery (\%) } \\
(n=5)\end{array}$} \\
\hline & & Linear Equation & $\mathrm{R}^{2}$ & Spiked Conc ( $\left.\mu \mathrm{g} \mathrm{L}^{-1}\right)$ & Accuracy (\%) & Precision (\%) & \\
\hline \multirow[t]{2}{*}{ bis-TMS-E1 } & 11.29 & $y=0.0707 x-0.0001$ & 0.9982 & 0.05 & 100 & 7.18 & $104 \pm 7.4$ \\
\hline & & & & 0.10 & 112 & 5.62 & $105 \pm 5.9$ \\
\hline \multirow[t]{2}{*}{ bis-TMS-E2 } & 11.42 & $y=0.0768 x+0.0003$ & 0.9979 & 0.05 & 104 & 10.8 & $93.0 \pm 10.0$ \\
\hline & & & & 0.10 & 101 & 4.74 & $106 \pm 5.0$ \\
\hline \multirow[t]{2}{*}{ tri-TMS-E3 } & 12.70 & $y=0.3431 x+0.0002$ & 0.9986 & 5.0 & 112 & 8.75 & $111 \pm 8.7$ \\
\hline & & & & 10.0 & 104 & 8.86 & $94.4 \pm 7.9$ \\
\hline \multirow[t]{2}{*}{ TMS-P } & 12.79 & $y=0.0315 x+0.0003$ & 0.9986 & 0.05 & 108 & 6.08 & $98.6 \pm 6.0$ \\
\hline & & & & 0.10 & 96.0 & 3.12 & $105 \pm 3.3$ \\
\hline \multirow[t]{2}{*}{ bis-TMS-T } & 11.45 & $y=0.1738 x+0.0037$ & 0.9986 & 0.05 & 108 & 6.76 & $101 \pm 4.2$ \\
\hline & & & & 0.10 & 97.0 & 6.00 & $108 \pm 4.8$ \\
\hline
\end{tabular}


Table 4 Comparison of analytical methods for determining natural steroidal compounds in saliva

\begin{tabular}{|c|c|c|c|c|c|c|c|}
\hline \multirow[t]{2}{*}{ Ref } & \multirow[t]{2}{*}{ Preparation method } & \multirow[t]{2}{*}{ Instrument } & \multicolumn{5}{|c|}{ The limit of quantification $(\mu \mathrm{g} / \mathrm{L})$} \\
\hline & & & E1 & E2 & E3 & $\mathbf{P}$ & $\mathbf{T}$ \\
\hline Hogg et al. 2005 [21] & SPE & LC-MS/MS & - & - & - & - & 0.5 \\
\hline Matsui et al. 2009 [12] & SPE & LC-MS/MS & - & - & - & - & 0.005 \\
\hline Shibayama et al. 2009 [4] & SPE & LC-MS/MS & - & - & - & - & 0.010 \\
\hline Gould et al. 1986 [23] & IA & GC-MS & - & - & - & - & $0.0013^{*}$ \\
\hline De Boever et al. 1988 [18] & - & EIA & - & - & $0.09^{*}$ & - & - \\
\hline Kivlighan et al. 2005 [16] & & EIA & & $0.001^{*}$ & & $0.005^{*}$ & \\
\hline This study & LLE & GC-MS & 0.003 & 0.002 & 0.3 & 0.003 & 0.003 \\
\hline
\end{tabular}

$\mathrm{IA}=$ Immunoadsorption

EIA: Enzyme Immunoassay

*the limit of detection

Table 5 Analytical results of natural steroidal hormones in saliva

\begin{tabular}{|c|c|c|c|c|c|c|c|c|}
\hline \multirow[t]{2}{*}{ Sample No } & \multirow[t]{2}{*}{ Gender } & \multirow[t]{2}{*}{ Age range (Mean Age) } & \multirow[t]{2}{*}{ Number } & \multicolumn{5}{|c|}{ Analytical results, mean \pm SD (ng/L) } \\
\hline & & & & Estrone & 17ß-Estradiol & Progesterone & Testosterone & Estriol \\
\hline Healthy volunteer & $\mathrm{F}$ & $21-45(32)$ & 5 & ND & $11 \pm 3$ & $17 \pm 7$ & $37 \pm 3$ & ND \\
\hline Healthy volunteer & M & $28-54(42)$ & 5 & ND & ND & ND & $116 \pm 49$ & ND \\
\hline Patient with prostatic carcinoma & M & $43-53(48)$ & 5 & ND & ND & ND & $12 \pm 9$ & ND \\
\hline
\end{tabular}

$\mathrm{F}=$ female, $\mathrm{M}=$ male, $\mathrm{SD}=$ standard deviation

Thus, it is concluded that the simultaneous monitoring of E1, E2, E3, P, and T using the proposed method can evaluate the increased risk of many hormone dependant disorders.

\section{Conclusions}

A sensitive and simultaneous method has been developed to analyze natural steroids in human saliva. The silylation derivatives of steroids containing multifunctional groups with MSTFA/ $\mathrm{NH}_{4} \mathrm{I}$ (100:2) containing dithioerythritol for $10 \mathrm{~min}$ at $90^{\circ} \mathrm{C}$ have good chromatographic properties and offer a single derivative product. The extraction of these compounds from saliva with pentane and dried sodium sulfate yields a high rate of recovery with a small degree of variation. Furthermore, the quantification of the steroids is excellent. The linear calibration curves cover a range of LOQ to $100 \mu \mathrm{g} / \mathrm{L}$, and the LOQs are 0.002 to $0.3 \mu \mathrm{g} / \mathrm{L}$ for a $1.0 \mathrm{~mL}$ sample of saliva. The natural steroids present in saliva were determined. In the present study, the suggested method enables the successful determination of trace amounts of natural steroidal compounds in saliva. The results suggest that the measurement of salivary E1, E2, E3, P, and $\mathrm{T}$ concentrations using the proposed method can evaluate the increased risk of various disorders.

\section{Author details}

${ }^{1}$ Department of Environmental Science, Kongju National University, Kongju, Korea 314-701, South Korea. ${ }^{2}$ Department of Environmental Education, Kongju National University, Kongju, Korea 314-701, South Korea.

\section{Authors' contributions}

HSS initiated and prepared the draft. JAO conducted the extraction and method developments. All authors designed the study. All authors contributed to data analyses and to finalizing the manuscript. All authors have read and approved the final version.

\section{Competing interests}

The authors declare that they have no competing interests.

Received: 17 February 2012 Accepted: 28 March 2012

Published: 28 March 2012

\section{References}

1. Arregger AL, Contreras LN, Tumilasci OR, Aquilano DR, Cardoso EML: Salivary testosterone: a reliable approach to the diagnosis of male hypogonadism. Clin Endocrinol 2007, 67:656-662.

2. Cardoso E, Persi G, Gonzalez N: Assessment of adrenal function by measurement of salivary steroids in response to corticotrophin in patients infected with human immunodeficiency virus. Steroids 2007, 72:328-334.

3. Yasuda M, Honma S, Furuya K: Diagnostic significance of salivary testosterone measurement revisited: using liquid chromatography/mass spectrometry and enzyme-linked immunosorbent assay. J Men Heal 2008, 5:56-63.

4. Shibayama $Y$, Higashi $T$, Shimada K: Simultaneous determination of salivary testosterone and dehydroepiandrosterone using LC-MS/MS: Method development and evaluation of applicability for diagnosis and medication for late-onset hypogonadism. J Chromatogr B 2009, 877:2615-2623.

5. Kaufman E, Lamster IB: The diagnostic applications of saliva-a review. Crit Rev Oral Biol Med 2002, 13:197-212.

6. Worthman CM, Stallings JF, Hofman LF: Sensitive salivary estradiol assay for monitoring ovarian function. Clin Chem 1990, 36:1769-1773.

7. Suri $R$, Hellemann $G$, Cohen L: Saliva estriol levels in women with and without prenatal antidepressant treatment. Biol Psych 2008, 64:533-553.

8. Klebanoff MA, Meis PJ: Salivary progesterone and estriol among pregnant women treated with 17-a-hydroxyprogesterone caproate or placebo. Am J Obstet Gynecol 2008, 199:506e1-506e7.

9. Ohtaki T, Moriyoshi M, Nakada K: Radioimmunoassay of saliva estrone sulfate in pregnant sows. J Vet Med Sci 1997, 59:759-763. 
10. Navarro MA, Aguiló FB: Salivary testosterone in prostatic carcinoma. J Urol 1989, 63:306-308.

11. Yasuda M, Furuya K, Yoshii T: Low testosterone level of middle-aged Japanese men - the association between low testosterone levels and quality-of-life. J Men Heal 2007, 4:149-155.

12. Matsui F, Eitetsu K, Kenrou Y: Liquid chromatography-tandem mass spectrometry (LC-MS/MS) assay for simultaneous measurement of salivary testosterone and cortisol in healthy men for utilization in the diagnosis of late-onset hypogonadism in males. Endocrine J 2009, 56:1083-1094.

13. Jensen MA, Hansen AM, Abrahamsson P: Development and evaluation of a liquid chromatography tandem mass spectrometry method for simultaneous determination of salivary melatonin, cortisol and testosterone. J Chromatogr B 2011, 25:2527-2532.

14. Ives SJ, Blegen M, Coughlin MA: Salivary estradiol, interleukin-6 production, and the relationship to substrate metabolism during exercise in females. Eur J Appl Physiol 2011, 8:1649-1658.

15. Dabbs JM: Salivary testosterone measurements: Reliability across hours, days, and weeks. Phys Behav 1990, 48:83-86.

16. Kivlighan KT, Granger DA, Schwartz EB: Blood contamination and the measurement of salivary progesterone and estradiol. Horm Behav 2005, 47:367-370.

17. Voss H: Saliva as a fluid for measurement of estriol levels. Am J Obstet Gynecol 1999, 180:S226-S231.

18. De Boever J, Ulrix W, Vandekerckhove D: Direct chemiluminescence immuoassay of estriol and progresterone and their ratio during pregnancy. Chemluminescence immunoassay for estriol in saliva. Anal Chim Acta 1998, 205:215-222.

19. Johnson SG, Joplin GF, Burrin JM: Direct assay for testosterone in saliva: Relationship with a direct serum free testosterone assay. Clin Chim Acto 1987, 163:309-318.

20. Nobuyuki K, Ikeda K, Honma S: Validation of salivary cortisol and testosterone assays in chimpanzees by liquid chromatography-tandem mass spectrometry. Am J Primat 2009, 71:696-706.

21. Hogg CJ, Vickers ER, Rogers TL: Determination of testosterone in saliva and blow of bottlenose dolphins (Tursiops truncatus) using liquid chromatography-mass spectrometry. J Chromatogr B 2005, 814:339-346.

22. Gaskell SJ, Pike AW, Griffiths K: Analysis of testosterone and dehydroepiandrosterone in saliva by gas chromatography-mass spectrometry. Steroids 1980, 36:219-228.

23. Gould VJ, Turkes AO, Gaskell S: Gas chromatography-mass spectrometric analysis of salivary testosterone with reference to diethylstilboestroltreated prostatic cancer patients. J Steroid Biochem 1986, 24:563-567.

24. Heine RP, McGregor JA, Goodwin TM, Artal R, Hayashi RH, Robertson PA, Varner MW: Serial salivary estriol to detect an increased risk of preterm birth. Obstet Gynecol 2000, 96:490-497. 